\section{THU0582 THE TNF RECEPTOR-ASSOCIATED PERIODIC SYNDROME (TRAPS): CLINICAL AND GENETIC CHARACTERIZATION OF A COHORT OF ADULTS DIAGNOSED OF TRAPS SYNDROME}

Alberto Ruiz Román ${ }^{1}$, Salvador García Morillo², Marco Montes Cano ${ }^{3}$, Clara Aguilera $\mathrm{Cros}^{1}$, Manuel Leon Luque ${ }^{1}$, Maria Jose Valenzuela Porcel ${ }^{1}$, Maria Arcila Duran ${ }^{1}$, Lara Mendez ${ }^{1}$, Isabel Madroñal García ${ }^{1} .{ }^{1}$ HOSPITAL VIRGEN DEL ROCIO, Rheumatology, Seville, Spain; ${ }^{2}$ HOSPITAL VIRGEN DEL ROCIO, Internal Medicine, Seville, Spain; ${ }^{3}$ HOSPITAL VIRGEN DEL ROCIO, Immunology, Seville, Spain

Background: Tumor necrosis factor receptor-associated periodic syndrome (TRAPS) is a disease that is included within of hereditary syndromes of periodic fever. It presents an autosomal dominant pattern of inheritance. It's due to mutations of TNFRSF1A gene. It is usually present in childhood although it can also appear in adulthood and it tends to cause high levels of acute phase reactants, fever, musculoskeletal symptoms (myalgias, arthralgias, arthritis), rash, abdominal pain, etc

Objectives: To describe the clinical characteristics and genetic variants of patients diagnosed with TRAPS syndrome in a cohort of patients with autoinflammatory syndromes with follow-up in a tertiary hospital from 2013 to the present

Methods: Retrospective descriptive study of adult patients diagnosed with autoinflammatory syndrome since 2013 (year of introduction of genetic tests in the hospital laboratory) until now. The data was obtained from the review of medical records. All patients with mutations in TNRFSF1A gene and clinically compatible with this diagnosis were reviewed

Results: Of a total of 44 adult patients diagnosed with hereditary syndromes of periodic fever (FMF, TRAPS, cryopyrinopathies, HIDS) and compatible genetic mutations (excluding polymorphisms), 13 (29.5\%) presented mutations in the TNFRSF1A gene. Of those 13 patients, 9 $(69.2 \%)$ were women. The most frequent mutations were the mutation in heterozygosis in exon 4 (p.R92Q) with 12 cases (92.3\%) and one case $(7.6 \%)$ with mutation in heterozygosis in exon 3 (p.P46L). The mean age at diagnosis was 27.92 years (IR $12-55$ years). 5 patients showed simultaneous genetic variants in other genes related to autoinflammatory syndromes. Signs and/or symptoms were myalgia and elevation of acutephase reactants with 12 patients (86\%) followed by fever and joint symptoms (arthralgias and/or arthritis) with 11 patients $(79 \%)$ were the most frequent. 2 patients (14\%) had conjunctivitis. 9 patients (64\%) presented cutaneous involvement. 2 cases (14\%) presented lymphadenopathy. Regarding treatment, 5 patients $(36 \%)$ had received treatment with biological therapy (anti-IL-1 or anti-TNF) and another 5 patients $(36 \%)$ had used colchicine. The corticoids were used in 6 patients (43\%)

Conclusion: The TRAPS syndrome is a clinical entity to consider when making a differential diagnosis in patients with suspected autoinflammatory syndrome, that present fever, acute phase reactants elevation, arthromyalgia and its confirmation diagnosis is with genetic test

Disclosure of Interests: None declared

DOI: 10.1136/annrheumdis-2019-eular.7036

\section{THU0583 EXPERIENCE OF ANAKINRA AND CANAKINUMAB IN PATIENTS WITH COLCHICINE-RESISTANT FAMILIAL MEDITERRANEAN FEVER AND COMPLICATED WITH AMYLOIDOSIS}

Ali Şahin ${ }^{1}$, Mehmet Emin Derin ${ }^{2}$, Fatih Albayrak ${ }^{2}$, Burak Karakaş2. ${ }^{1}$ Sivas Cumhuriyet University, Rheumatology-Internal Medicine, sivas, Turkey, ${ }^{2}$ Sivas Cumhuriyet University, sivas, Turkey

Background: Familial Mediterranean Fever (FMF) is a hereditary autoinflammatory disease characterized by recurrent fever and serosal inflammation (1). The goal of FMF treatment is to prevent the attacks and to minimize subclinical inflammation between attacks, and in attacks-free period. Colchicine is a major drug that sine qua non in the treatment of FMF. However, anti-interleukin-1 agents are recommended in colchicine resistant and/or intolerant FMF patients (2).

Objectives: The aim of this study is to evaluate the efficacy of anti-interleukin-1 (anti-IL-1) agents in 54 FMF patients with resistant/intolareted to colchicine or complicated with amyloidosis.

Methods: Between January 2014 and December 2018, fifty four patients who were diagnosed as FMF according to the criteria of Tel-Hashomer that following-up at Sivas Cumhuriyet University Medical Faculty, Rheumatology-Internal Medicine Department were included in to the study.

Results: $25(46.3 \%)$ male and $29(53.7 \%)$ female were included in the study. The median age of the patients was 29 (min:17-max: 60) years and the median age at diagnosis was 18 (min: 3-max: 46) years. Anakinra was used in $34(63 \%)$ FMF patients $(100 \mathrm{mg} /$ day $)$, and canakinumab was used in $20(37 \%)$ patients $(150 \mathrm{mg} / 8$ weeks). 37 cases were resistant to colchicine, 8 were intolerant to colchicine, $9(20 \%)$ cases were comlicated with amyloidosis. 8 patients had renal transplantation. MEFV gene mutations are shown in Table 1. Median duration of anti-IL-1 agent use was 12 months (min:2-max40). 5 patients were resistant to anakinra, 4 patients had side effects which anakinra related. After a median follow up 12 months overall clinical response was\%95 (frequency of attacks $<1 / 6$ months). Median proteinuria decreased from 3850 $\mathrm{mg} /$ day to median $1600 \mathrm{mg} /$ day $(\mathrm{p}=0.04$ ) (Table 2). IL-6 treatment was started in 3 patients because of ineffectiveness of canakinumab. One pregnant patient was followed up with anakinra during pregnancy and there were no problems.

Conclusion: Anti-interleukin-1 agents can be used effectively and safely in the treatment of FMF patients. These agents are especially effective in the treatment of proteinuria due to amyloidosis. Large and long-lasting follow-up studies are needed to evaluate long-term effects of these drugs.

\section{REFERENCES}

[1] Ozdogan H, Ugurlu S. Familial Mediterranean Fever. Presse Med. 2019 Jan 24. pii: S0755-4982(18)30486-X. doi: 10.1016/j.lpm.2018.08.014. [Epub ahead of print]

[2] Seza Özen ve ark. EULAR recommendations for the management of familial Mediterranean fever. Ann Rheum Dis. 2016 Apr;75(4):644-51

Table 1. MEFV mutations in FMF patients

\begin{tabular}{lc}
\hline MEFV Mutations & $\mathbf{n}$ \\
\hline M694V homozygus & $20(37 \%)$ \\
M694V heterozygous & $8(15 \%)$ \\
Compound mutation & $14(26 \%)$ \\
Other mutation & $8(15 \%)$ \\
No mutation & $4(8 \%)$ \\
\hline
\end{tabular}

Table 2. Laboratory Findings of the FMF patients treated with anti-IL-1 agents

\begin{tabular}{lccc}
\hline & $\begin{array}{c}\text { Pre- } \\
\text { treatment } \\
\text { (median) }\end{array}$ & $\begin{array}{c}\text { Post- } \\
\text { Treatment } \\
\text { (median) }\end{array}$ & $\mathrm{p}$ \\
\hline Number of attacks & $>2 / 6$ month & $<1 / 6$ month & $\mathrm{p}<0.05$ \\
ESR mm/h & 33 & 8 & $\mathrm{p}<0.05$ \\
CRP mg/dl & 43 & 4.3 & $\mathrm{p}<0.05$ \\
Proteinuria mg/ & 3856 & 1600 & $\mathrm{p}<0.05$ \\
day & & & \\
\hline
\end{tabular}

Disclosure of Interests: None declared

DOI: 10.1136/annrheumdis-2019-eular.4760

\section{THU0584 RHEUMATOLOGICAL IMMUNE-RELATED ADVERSE EVENTS ASSOCIADTED WITH IMMUNOTHERAPY IN SOLID ORGAN TUMOR. STUDY OF 102 CASES FROM A REFERRAL SINGLE CENTER FOR LAST 4 YEARS}

Lara Sánchez Bilbao ${ }^{1}$, Iñigo González-Mazón ${ }^{1}$, Rosalía Demetrio-Pablo² ${ }^{2}$ José Luis Martín-Varillas ${ }^{1}$, Marina Delgado Ruiz ${ }^{3}$, Isabel Bernat Piña ${ }^{3}$, Belén AtienzaMateo ${ }^{1}$, Monica Calderón-Goercke ${ }^{1}$, D. Prieto-Peña ${ }^{1}$, Almudena García Castaño ${ }^{3}$, Miguel A González-Gay ${ }^{1}$, Ricardo Blanco ${ }^{1}{ }^{1}$ Marqués de Valdecilla University Hospital, Rheumatology, Santander, Spain; ${ }^{2}$ Marqués de Valdecilla University Hospital, Ophtalmology, Santander, Spain; ${ }^{3}$ Marqués de Valdecilla University Hospital, Oncology, Santander, Spain

Background: Immune checkpoint blockade therapy (ICBT) currently is one of the most used therapies against cancer. The activation of the immune system can lead to different immune-related adverse events (irAEs), being the rheumatological side effects among the most common.

Objectives: Our aim was to assess the rheumatological irAEs in patients who received immunotherapy.

Methods: We set up an observational study of patients treated with Nivolumab and Pembrolizumab (anti-PD1), Atezolizumab (anti-PD-L1) and Ipilimumab (antiCTLA-4) for solid organ tumors. All these patients were followed in a single reference University Hospital from March-2015 up to December-2018. The main outcome was to determinate the incidence of rheumatological irAEs.

Results: We studied 102 patients $\left(63^{\pi} / 39\right.$ 우 $)$ with a mean age of 60.6 \pm 9.7 with different solid organ tumors. Only 7 patients $(6.8 \%)$ had a previous diagnosis of an immune-mediated disease: psoriasis $(n=2)$, psoriatic arthritis (1), systemic lupus erythematosus (1), spondyloarthitis (1), rheumatoid arthritis (1) and skin lupus (1) 